\section{Comparison of Container Placement Patterns for Maximizing Greenhouse Space Use}

\author{
Elizabeth Will, ${ }^{1}$ James E. Faust, ${ }^{1}$ \\ and Benali B. Burgoa ${ }^{2}$
}

ADDITIONAL INDEX WORDS. efficiency, bench dimensions, staggered spacing, square spacing

Summary. A series of equations were developed to provide a convenient means to calculate the number of containers that can be placed into a specified area using three different placement patterns. The calculations require three pieces of information; the container spacing, i.e., distance between the center of one container and the center of the neighboring container, and the length and width of the greenhouse bench or floor area. The solutions allow comparisons of the total number of containers that will fit into that area using three different placement patterns: square, longstaggered, and short-staggered. In general, the closer the container spacing or the larger the production area, the greater the benefit of staggered spacing compared to square spacing. Staggered spacing frequently allows for up to $13 \%$ more containers to fit into a given area than square spacing; however, calculations must be made for specific situations to determine the most efficient spacing pattern. Cost analyses were performed on a range of container spacings and greenhouse dimensions. Spacing pattern can affect overhead costs from $\$ 0.02$ to $\$ 0.20$ per container for a 10 week crop. A spreadsheet, Bench C rop Calculator, is available from the authors for providing assistance in performing the calculations.

The cost of publishing this paper was defrayed in part by payment of page charges. U nder postal regulations, this paper therefore must be hereby marked advertise ment solely to indicate this fact.

${ }^{1}$ D epartment of $\mathrm{O}$ rnamental $\mathrm{H}$ orticulture and $\mathrm{L}$ and scape D esign, The U niversity of T ennessee, Knoxville, TN 37901.

${ }^{2}$ CD M Federal, O ak Ridge, TN 37830. verhead costs (including equipment, taxes, and utilities) are a significant part of total greenhouse crop-production costs. The overhead cost per square foot per week of bench space has been estimated to be $\$ 0.20$ (Brumfield, 1995). Since overhead costs remain constant in a given location regardless of the crop or thenumber of containersproduced, the efficiency with which growing space is used in order to minimize overhead costs per plant is important.

Efficient use of greenhouse space requires knowing how many plants will fit on a bench or floor so that each plant has sufficient space to grow. Containers are spaced by commercial growers on squareor staggered spacing. Squarespacing is frequently employed since this method is considerably easier for workersto perform accurately. Also, growers usually assume square spacing when planning for the number of containers that will fit in a greenhouse, since the calculation is relatively simple.

We are unaware of an available process through which growers can determine how to place containers on a bench or floor in such a way that the space is used most efficiently. The objective of this project was to develop a decision-support tool to calculate the maximum number of containers that can be placed in a specified area. The equations could be entered in a spreadsheet to allow growers to determine the most efficient spacing pattern for their individual situations or a spreadsheet, named Bench Space C alculator, is available from the authors.

\section{Materials and methods}

There are three commonly used patterns of container placement (Fig. 1). Square placement involves placing containers in parallel rows perpendicular to each other in both directions on the growing surface so that any four containersform asquare. Theother two patterns involve placing containers in staggered arrangements in which any three containers form an equilateral triangle. In the long-staggered pattern, the rows of containers are parallel to the long dimension of the bench or floor space. In the short-staggered pattern, therows of containers are parallel to the short dimension of the bench or floor space.

We developed aseries of equations to calculate the number of containers fitting in agiven areain each of the three 


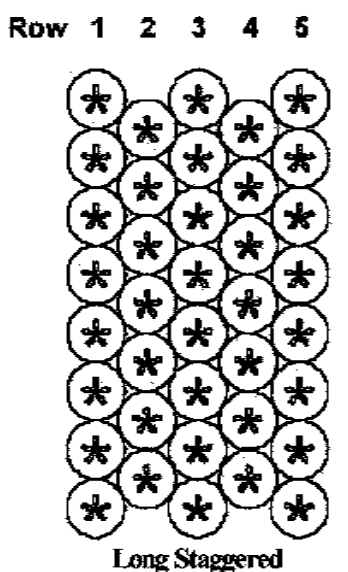

Long Stagoered

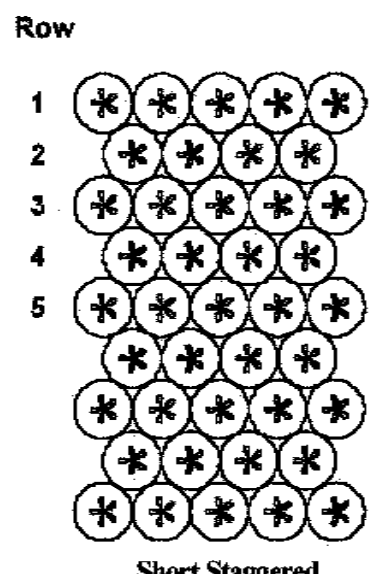

Short Staggered

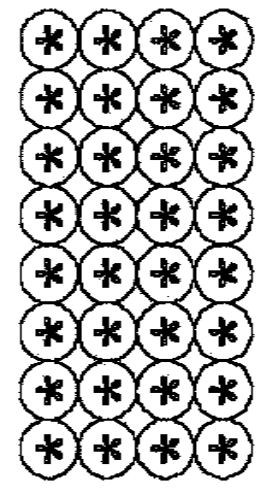

Square

Fig. 1. Three possible arrangements of containers: long staggered, short staggered, and square. R ows are numbered sequentially.

arrangements. Equation inputs are the length (feet; $1.0 \mathrm{ft}=0.3048 \mathrm{~m}$ ) and width (feet) of usable area and the container spacing (inches; 1.0 inch $=2.54$ $\mathrm{cm})$, i.e., the distance from the center of one container to the center of the next container.

SHORT-STAGgered PATtern. Equations 1 to 6 are used to cal culatethetotal number of rows of containers [Eq. 1] (Fig. 1B), the number of odd-numbered [Eq. 2] and even-numbered rows [Eq. 3], the number of containers fitting in odd-numbered rows [Eq. 4] and in even-numbered rows [Eq. 5], and the total number of containersfitting in the specified area [Eq. 6] using the short-staggered arrangement pattern.

$\mathrm{N}$ umber of rows $=[$ long dimension $(0.01083 \times$ container spacing $)] /$ ( $0.0725 \times$ container spacing)

In Eq. [1], the solution isrounded down to the nearest whole number. N umber of odd-numbered rows =number of rows/ 2

$U$ setherounded solution for number of rows in Eq. 1. The solution for Eq. 2 isrounded up to thenearest whole number.

N umber of even-numbered rows=number of rows/ 2

$U$ setherounded solution for number of rows in Eq. 1. The solution for Eq. 3 is rounded down to the nearest whole number.

N umber of containersin odd-numbered rows $=($ short dimension $\times 12) /$ container spacing

The solution for Eq. 4 is rounded down to the nearest whole number. $\mathrm{N}$ umber of containers in even-numbered rows $=$ [ short dimension $0.04167 \times$ container spacing)]/ ( $0.08333 \times$ container spacing)
The solution for Eq. 5 is rounded down to the nearest whole number.

T otal number of containers $=$ (number of odd-numbered rows) $\times$ (number of containers in odd-numbered rows + number of even-numbered rows $\times$ number of containers in even-numbered rows) [6]

$U$ se rounded answers to Eqs. 2 to 5 when calculating a solution for Eq. 6 .

LoNG-STAGgered PatTERN. Equations 7 to 12 are used to calculate the total number of rows of containers [Eq. 7] (Fig. 1A), the number of odd-numbered [E q. 8] and even-numbered rows [Eq. 9], the number of containers fitting in odd-numbered rows [Eq. 10] and in even-numbered rows [Eq. 11], and the total number of containers fitting in the specified area [Eq. 12] using the long-staggered arrangement pattern.

$\mathrm{N}$ umber of rows $=[$ short dimension $(0.01083 \times$ container spacing $)] /$ $(0.0725 \times$ container spacing $) \quad$ [7]

In Eq. [7], the solution isrounded down to the nearest whole number. $\mathrm{N}$ umber of odd-numbered rows $=$ number of rows/ 2

$U$ setherounded solution for number of rows in Eq. 7. The solution for Eq. 8 isrounded up to thenearest whole number.

N umber of even-numbered rows=number of rows/ 2

[9]

$U$ setherounded solution for number of rows in Eq. 7. The solution for Eq. 9 is rounded down to the nearest whole number.

$\mathrm{N}$ umber of containersin odd-numbered rows $=($ long dimension $\times 12) /$ container spacing

[10]

Thesolution for Eq. 10 is rounded down to the nearest whole number.
N umber of containers in even-numbered rows $=$ [ long dimension -0.04167 $\times$ container spacing $)] /(0.08333 \times$ container spacing)

Thesolution for $E q .11$ is rounded down to the nearest whole number. Total number of containers $=$ (number of odd-numbered rows $x$ number of containers in odd-numbered rows) + (number of even-numbered rows $\times$ number of containers in even-numbered rows)

$U$ se rounded answers to Eqs. 8 to 11 when calculating a solution for $\mathrm{Eq}$. 12.

Square patTern. Equations 13 to 15 are used to calculate the number of rows of containers using the short dimension of the area [Eq. 13] (Fig. 1C), the number of containers fitting in each row [Eq. 14] and the total number of containers fitting into the given area using the square spacing arrangement [Eq. 15].

$\mathrm{N}$ umber of rows = short dimension/ container spacing

Thesolution for Eq. 13 is rounded down to the nearest whole number. N umber of containers per row $=$ long dimension/ container

Thesolution for Eq. 14 is rounded down to the nearest whole number. Total number of containers $=$ number of rows $\times$ number of containersper row [15]

$\mathrm{U}$ serounded answers to $\mathrm{E} q \mathrm{qs} .13$ to 14 when calculating a solution for $\mathrm{Eq}$. 15.

The number of containers placed at various spacings that fit in different sized areas were compared to illustrate the application of the model for maximizing space use(T able1). Cost analyses were also conducted to illustrate the potential economic impact of the different spacing patterns.

\section{Results and discussion}

The most common means of estimating the number of containersfitting into a specific area entailscal culating the bench or floor area (length $\times$ width) and dividing this valueby the container area, calculated as the square of the container spacing. For example, using a6-ft (1.83$\mathrm{m}) \times 10$ - $\mathrm{ft}(3.05-\mathrm{m})$ bench $\left[60 \mathrm{ft}^{2}(5.57\right.$ $\left.\left.\mathrm{m}^{2}\right)\right]$ and 14 -inch $(35.6-\mathrm{cm})$ spacing on the crop [ $1.36 \mathrm{ft}^{2}\left(0.126 \mathrm{~m}^{2}\right)$ per container], thenumber of containerscalculated to fit in this area is $44(60 / 1.36)$. This answer is incorrect. $U$ sing a square spacing pattern, only five rows of containers placed on 14-inch $(35.6 \mathrm{~cm})$ spacing will fit along the short (6 ft) 
dimension of the bench resulting in a lossof two inches [ 70 inches $(177.8 \mathrm{~cm}$ ) used while 72 inches $(182.9 \mathrm{~cm})$ are available]. O nly eight rows will fit along the long ( $10 \mathrm{ft}$ ) dimension resulting in wasting 8 inches [ 112 inches $(2.85 \mathrm{~m})$ used while 120 inches $(3.05 \mathrm{~m})$ are available]. Thus, only 40 plants can actually fit on thisbench using thesquare pattern. The error results from assuming that the plants will occupy every square inch of space available. Therefore, themost common meansfor growers to estimate container numbers fitting in a given area is inaccurate.

A staggered arrangement frequently allows a significant increase in the number of containers fitting in a given area, ascompared to square placement (Table 1). For example, the num- ber of 6 -inch $(15.2 \mathrm{~cm})$ containers fitting pot-to-pot in a $6 \times 20-\mathrm{ft}(1.83 \times$ $6.10-\mathrm{m}$ ) area is $7.1 \%$ and $7.9 \%$ greater when arranged in long-staggered and short-staggered patterns compared to the square pattern. In fact, the only examples in which the square spacing was more efficient than the staggered spacing were when the containers were placed on relatively small bench or floor areas at 12 -inch $(30.5-\mathrm{cm})$ spacing.

Theadvantage of astaggered compared to square arrangement frequently increases with increasing area (T able 1). For example, when comparing containers placed at 6 -inch $(15.2-\mathrm{cm})$ spacing, the percent increase in container number of the short-staggered pattern versus the square pattern ranges from $3.1 \%$ on the $4 \times 10$-ft $(1.22 \times 3.05 \mathrm{~m})$ bench to $13.1 \%$ on the $20 \times 100$-ft $(6.10 \times 30.5$ $\mathrm{m})$ area. In general, thedimensionsused in Table 1 that reflect typical greenhouse floor sizes often display greater percentage increases in container number using staggered versus square spacing compared to the dimensionstypical of benches. A pplication of these calculations to overwintering of containerized perennials and woody plants calculated $15 \%$ to $20 \%$ increases in containers accommodated in typical cold frame polyhouses using staggered patterns compared to square patterns (Will and Faust, 1996).

Relatively small differences in total container number were observed between long- and short-staggered patterns. Typically, the difference in container number between short-staggered and long-staggered arrangements was

Table 1. N umber of containers fitting on benches or floors of various dimensions in square (S), short-staggered (SS), and long-staggered (LS) arrangements (E qs. [6], [12], and [15]). N umbers in parentheses indicate the percentage change in the number of containers compared to square placement. The cost analyses use overhead costs of $\$ 0.20 / \mathrm{ft}^{2}$ per week and a 10 -week crop. ${ }^{2}$

\begin{tabular}{|c|c|c|c|c|c|c|c|c|c|c|}
\hline \multirow{2}{*}{$\begin{array}{l}\text { Container } \\
\text { diam } \\
\text { or } \\
\text { spacing } \\
\text { (inch) }\end{array}$} & \multicolumn{2}{|c|}{$\begin{array}{c}\text { Bench } \\
\text { or } \\
\text { floor } \\
\text { dimensions } \\
\text { (ft) }\end{array}$} & \multicolumn{3}{|c|}{$\begin{array}{c}\text { Total } \\
\text { containers/ } \\
\text { bench } \\
\text { (\% change } \\
\text { compared to } \\
\text { S arrangement) }\end{array}$} & \multicolumn{3}{|c|}{$\begin{array}{l}\text { Cost/ } \\
\text { container } \\
\text { (\$) }\end{array}$} & \multicolumn{2}{|c|}{$\begin{array}{c}\text { Savings } \\
\text { (\$ loss)/ } \\
\text { bench } \\
\text { compared to } \\
\text { S arrangement) }\end{array}$} \\
\hline & Width & Length & 5 & SS & LS & 5 & SS & LS & SS & LS \\
\hline 4 & 4 & 10 & 360 & $391(8.6)$ & $384(6.7)$ & 0.22 & 0.20 & 0.21 & 6.89 & 5.33 \\
\hline 4 & 6 & 10 & 540 & $595(10.2)$ & $590(9.3)$ & 0.22 & 0.20 & 0.20 & 12.22 & 11.11 \\
\hline 4 & 6 & 20 & 1080 & $1190(10.2)$ & $1190(10.2)$ & 0.22 & 0.20 & 0.20 & 24.44 & 24.44 \\
\hline 4 & 6 & 50 & 2700 & 3010 (11.5) & $2990(10.7)$ & 0.22 & 0.20 & 0.20 & 68.89 & 64.44 \\
\hline 4 & 10 & 100 & 9000 & $10148(12.8)$ & $10183(13.1)$ & 0.22 & 0.20 & 0.20 & 255.11 & 262.89 \\
\hline 4 & 15 & 100 & 13500 & $15308(13.4)$ & 15275 (13.2) & 0.22 & 0.20 & 0.20 & 401.78 & 394.44 \\
\hline 4 & 20 & 100 & 18000 & $20468(13.7)$ & 20366 (13.1) & 0.22 & 0.20 & 0.20 & 548.44 & 525.78 \\
\hline 6 & 4 & 10 & 160 & $165(3.1)$ & $176(10.0)$ & 0.50 & 0.48 & 0.45 & 2.50 & 8.00 \\
\hline 6 & 6 & 10 & 240 & $253(5.4)$ & $254(5.8)$ & 0.50 & 0.47 & 0.47 & 6.50 & 7.00 \\
\hline 6 & 6 & 20 & 480 & $518(7.9)$ & $514(7.1)$ & 0.50 & 0.46 & 0.47 & 19.00 & 17.00 \\
\hline 6 & 6 & 50 & 1200 & $1311(9.3)$ & $1294(7.8)$ & 0.50 & 0.46 & 0.46 & 55.50 & 47.00 \\
\hline 6 & 10 & 100 & 4000 & 4466 (11.7) & $4389(9.7)$ & 0.50 & 0.45 & 0.46 & 233.00 & 194.50 \\
\hline 6 & 15 & 100 & 6000 & 6756 (12.6) & $6783(13.1)$ & 0.50 & 0.44 & 0.44 & 378.00 & 391.50 \\
\hline 6 & 20 & 100 & 8000 & 9046 (13.1) & $8978(12.2)$ & 0.50 & 0.44 & 0.45 & 523.00 & 489.00 \\
\hline 10 & 4 & 10 & 48 & $52(8.3)$ & $58(20.8)$ & 1.67 & 1.54 & 1.38 & 6.67 & 16.67 \\
\hline 10 & 6 & 10 & 84 & $85(1.2)$ & $92(9.5)$ & 1.43 & 1.41 & 1.30 & 1.43 & 11.43 \\
\hline 10 & 6 & 20 & 168 & $176(4.8)$ & 188 (11.9) & 1.43 & 1.36 & 1.28 & 11.43 & 28.57 \\
\hline 10 & 6 & 50 & 420 & $442(5.2)$ & 476 (13.3) & 1.43 & 1.36 & 1.26 & 31.43 & 80.00 \\
\hline 10 & 10 & 100 & 1440 & $1576(9.4)$ & $1554(7.9)$ & 1.39 & 1.27 & 1.29 & 188.89 & 158.33 \\
\hline 10 & 15 & 100 & 2160 & 2398 (11.0) & $2390(10.7)$ & 1.39 & 1.25 & 1.26 & 330.56 & 319.44 \\
\hline 10 & 20 & 100 & 2880 & $3220(11.8)$ & $3227(12.1)$ & 1.39 & 1.24 & 1.24 & 472.22 & 481.94 \\
\hline 12 & 4 & 10 & 40 & $39(-2.5)$ & $38(-5.0)$ & 2.00 & 2.05 & 2.11 & $(2.00)$ & $(4.00)$ \\
\hline 12 & 6 & 10 & 60 & $61(1.7)$ & $57(-5.0)$ & 2.00 & 1.97 & 2.11 & 2.00 & $(6.00)$ \\
\hline 12 & 6 & 20 & 120 & $121(0.8)$ & $117(-2.5)$ & 2.00 & 1.98 & 2.05 & 2.00 & $(6.00)$ \\
\hline 12 & 6 & 50 & 300 & $314(4.7)$ & $297(-1.0)$ & 2.00 & 1.91 & 2.02 & 28.00 & $(6.00)$ \\
\hline 12 & 10 & 100 & 1000 & $1083(8.3)$ & 1095 (9.5) & 2.00 & 1.85 & 1.83 & 166.00 & 190.00 \\
\hline 12 & 15 & 100 & 1500 & $1653(10.2)$ & $1692(12.8)$ & 2.00 & 1.81 & 1.77 & 306.00 & 384.00 \\
\hline 12 & 20 & 100 & 2000 & $2223(11.2)$ & 2189 (9.5) & 2.00 & 1.80 & 1.83 & 446.00 & 378.00 \\
\hline
\end{tabular}

zThe numbers in this table indicate the final rounded solutions; however, rounding errors can occur if the rounded solutions are inappropriately used for further calculations. See text for discussion concerning rounding errors. 


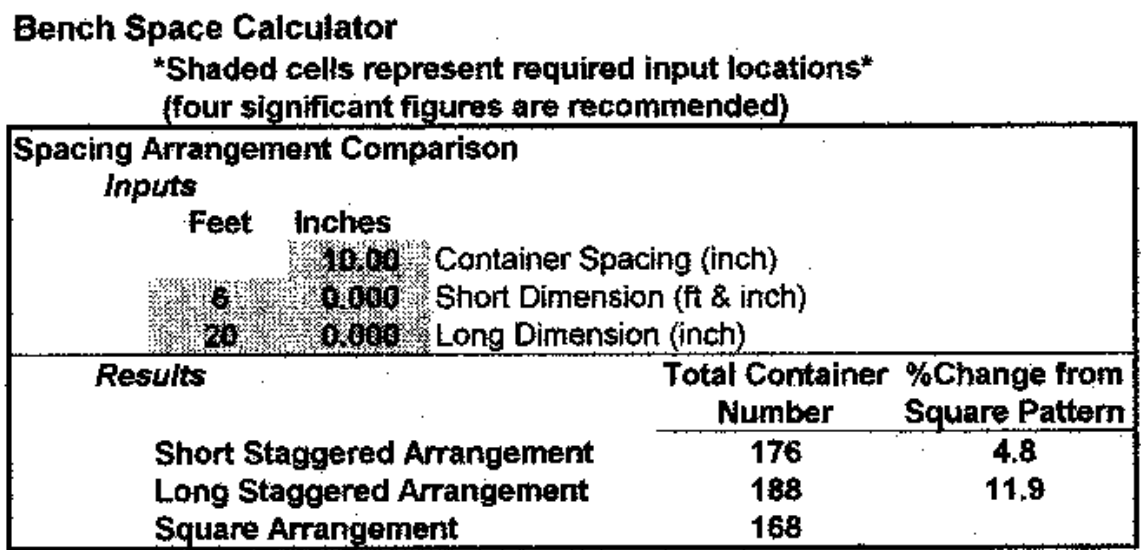

\begin{tabular}{|c|c|c|}
\hline \multicolumn{3}{|c|}{ 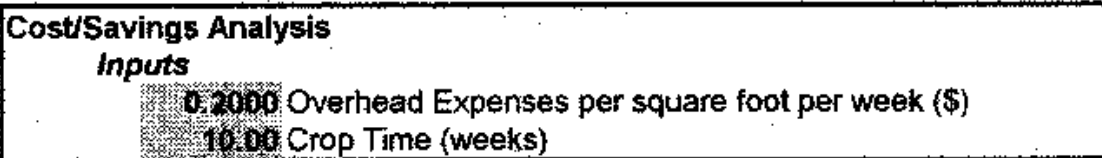 } \\
\hline Results & $\begin{array}{l}\text { Cost per } \\
\text { Container } \\
\text { (\$) }\end{array}$ & $\begin{array}{l}\text { Savings/Loss } \\
\text { per Bench (\$) } \\
\text { (compared to } \\
\text { Square) }\end{array}$ \\
\hline $\begin{array}{l}\text { Short Staggered Arrangement } \\
\text { Long Staggered Arrangement } \\
\text { Square Arrangement }\end{array}$ & $\begin{array}{l}1.364 \\
1.277 \\
1.429\end{array}$ & $\begin{array}{l}11.43 \\
28.57\end{array}$ \\
\hline
\end{tabular}

Fig. 2. A view of the Bench C rop C alculator spreadsheet developed to assist users with container-spacing and cost-analysis calculations ( 1 inch $=2.54 \mathrm{~cm}, 1$ $\mathrm{ft}=0.3048 \mathrm{~m}$ ). This M icrosoft Excel spreadsheet is available from the authors.

$<3 \%$ The most efficient staggered pattern varies with the bench dimensions, i.e., no consistent pattern was observed.

While performing the calculations, keep in mind that calculations may not al waysreflect reality. For example, if one extra row of containers can not fit onto a bench because it is just $1 \mathrm{~mm}(0.0394$ inch) too wide, then dozens of containers can be lost. While in reality, one could easily bend a plastic container 1 $\mathrm{mm}$ to force an extra row onto a bench. Therefore, accurate measurements of container diameters or spacings is important, since small changes in container diameter can have a relatively large impact on the number of containers fitting on a specific bench. Similarly, accuracy can belost when an insufficient number of significant figures are used when converting the length measurement to or from metric units. For example, a 10-cm container is often considered to be a 4-inch container; however, the unit conversion results in a calculated 3.937-inch container. U sing 4.000 versus 3.937 results in slightly different solutions. Consequently, four significant figures are recommended, although three are acceptable in most circumstances.

Increase in the number of contain- ers fitting on a bench in a staggered arrangement as compared to square placement results in a $13 \%$ reduction in growing area per plant. This reduction in area per plant is independent of container size. It is based on the ratio of the polygonal growing space in staggered placement to the square growing space in square placement. The area of the square growing space of a plant placed pot-to-pot in square placement is equal to the diameter of the container squared $\left(A=d^{2}\right)$. The area of the hexagonal growing space of a plant placed pot-topot in staggered placement is equal to 0.87 timesthediameter of thecontainer squared $\left(A=0.87 d^{2}\right)$. Because the additional space in the square pattern is in the corners of the growing area of each plant, losing this space is not important to the development of a wellshaped plant. Light interception by plants in the staggered patterns is more efficient than in thesquarepattern where leaf overlapping would begin beforethe corners of the square were filled in.

Cost analyses were performed to demonstrate the potential savings from different spacing situations (Table 1 ). These analyses examine the effect of the spacing pattern on threedifferent bench or floor dimensions where the overhead square foot cost per week is $\$ 0.20$ and a 10 -week crop isgrown at 12-inch (30.5$\mathrm{cm})$ spacing. The cost per container at the 4 -inch $(10.2-\mathrm{cm})$ spacing wasmostly affected by the container spacing, not the bench or floor dimensions. For example, cost per container at the 4-inch (10.2-cm) spacing wastypicallylessthan or equal to $\$ 0.02$ difference between spacing patterns regardless on bench dimensions. While, the cost per container for the 12 -inch $(30.5-\mathrm{cm}) \mathrm{spac}-$ ing was greatly affected by spacing patterns and bench dimensions, ranging from a $\$ 0.02$ to $\$ 0.23$ difference be tween the different combinations.

The savings or loss per bench as a result of the spacing pattern isalso demonstrated in Table 1. Savings per bench was as high as \$548 when comparing short-staggered to square spacing in the $20 \times 100 \mathrm{ft}(6.10 \times 30.5 \mathrm{~m})$ growing area. These savings estimates indicate that spacing pattern can have a significant economic impact.

Equations 1 to 15 can be entered into a spreadsheet to allow for comparisons between different greenhouse bench and crop situations. A M icrosoft Excel spreadsheet has been developed and is available from the authors (Fig. 2). The user must provide three measurements including container spacing (inches) and the short and long dimensions of the bench or floor area (feet and inches). The spreadsheet will calculate the total container number and percent change comparing the staggered patterns to the square pattern. Cost and savings analysis can be calculated by inputting the estimated overhead expenses per square foot per week and the crop time, i.e., the number of weeks on the bench. The spreadsheet then calculates the cost per container and the savingsor loss per bench comparing the staggered patterns to the square pattern. Space is provided in the spreadsheet cells for four significant figures to be entered. Significant rounding errors can occur if fewer figures are used. This is especially the case when converting units from metric measurements.

\section{Literature cited}

Brumfield, R.G. 1995. Production costs, p. 197-211. I n: W. Banner and M. Klopmeyer (eds.). N ew Guinea impatiens: A B all guide. Ball Publ., Batavia, III.

Will, E. and J.E. Faust. 1996. M aximizing efficiency of greenhouse space use. Proc. S. N ursery Assn. Res. Conf. 41:123-127. 